Document downloaded from:

http://hdl.handle.net/10251/62571

This paper must be cited as:

E. De la Poza Plaza; Jódar Sánchez, LA.; MOHAMMED SALEH SALIM (2015). Modelling the propagation of adult male muscle dysmorphia in Spain: economic, emotional and social drivers. Applied Economics. 47(12):1159-1169. doi:10.1080/00036846.2013.870657.

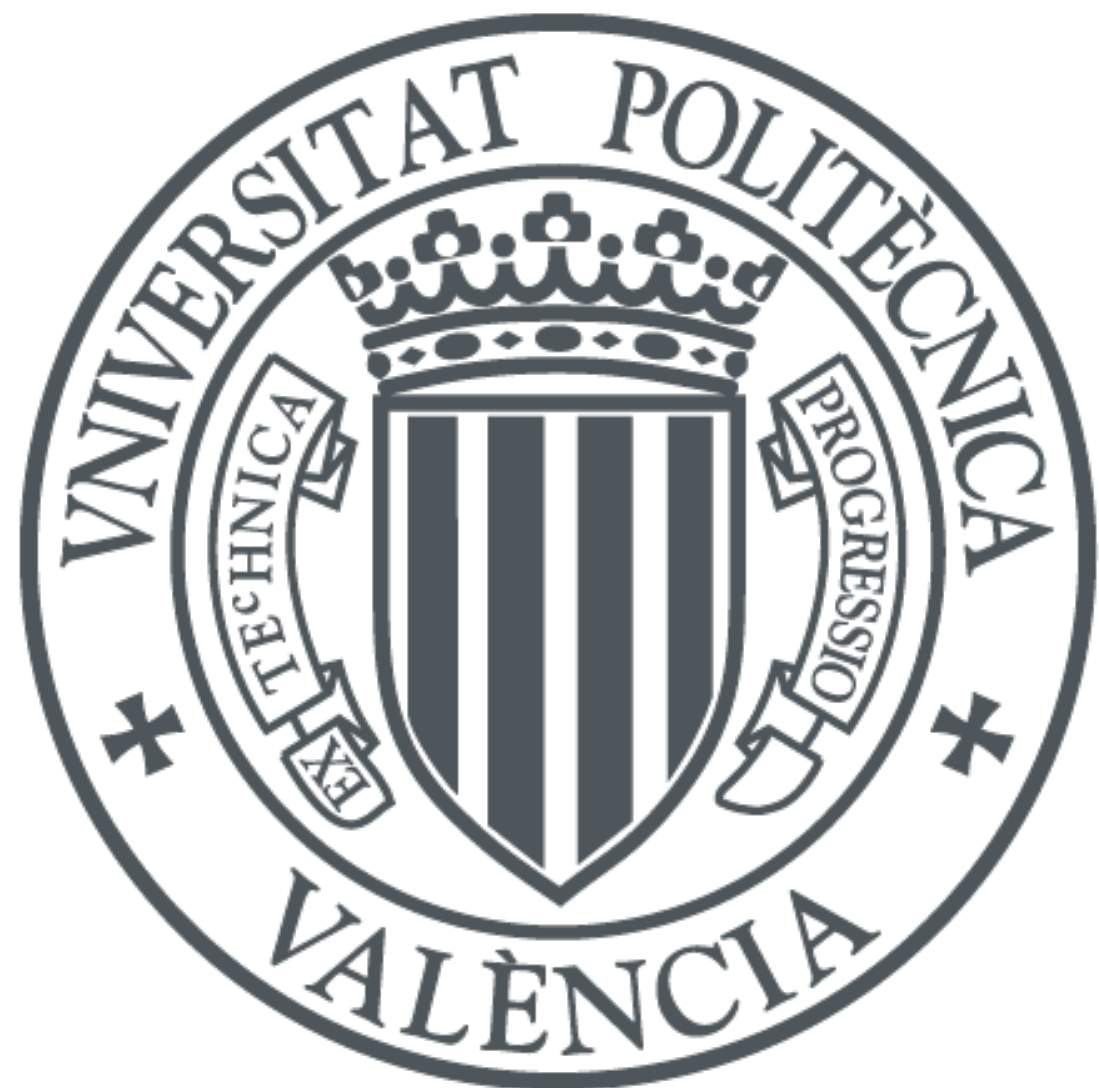

The final publication is available at

http://dx.doi.org/10.1080/00036846.2013.870657

Copyright Taylor \& Francis (Routledge): SSH Titles

Additional Information

This is an author's accepted manuscript of an article published in:

"Applied Economics"; Volume 47, Issue 12, 2015; copyright Taylor \& Francis; available online at: http://dx.doi.org/10.1080/00036846.2013.870657 


\title{
Modelling the propagation of adult male muscle dysmorphia in Spain: economic, emotional and social drivers.
}

\author{
E. De la Poza ${ }^{*}$, L. Jódar ${ }^{2}$, M.S.S. Alkasadi² \\ ${ }^{1}$ Facultad de Administración y Dirección de Empresas, Universitat Politècnica de València, \\ Building 7J. Camino de Vera s/n. 46022, Valencia, Spain. \\ ${ }_{2}^{2}$ Instituto Universitario de Matemática Multidisciplinar, Universitat Politècnica de València. \\ Building 8G. Camino de Vera s/n. 46022, Valencia, Spain.
}

\begin{abstract}
Males aged over 40 do more gym practice to improve their body image as a way of reinforcing their personal self-esteem and sexual appeal.

Cases when self-image becomes an obsession may result in a body dysmorphic disorder named Muscle Dysmorphia (MD). The combination of psychological, environmental and biological drivers determines the appearance and development of this disorder.

In this paper we developed a discrete population mathematical model to forecast the rate of prevalence of males who are non-competitive bodybuilders at risk of suffering MD in Spain in forthcoming years. Economic, emotional, sociological, and psychological motivations were taken into account to quantify the dynamic behaviour of Spanish non-competitive bodybuilders.

The impact of the unemployment is reflected in the construction of two coefficients, $\alpha_{u}$ and $\alpha_{21}$, which explain subpopulation transits due to the economy. Sociological influences, such as human herding and social propagation, were also considered.

Our results predict an increase in Spanish non-competitive bodybuilders suffering MD from 1\% in 2011 to around $11 \%$ in 2015 . Our model can be applied to any other western country where data are available, and to another study period when the hypotheses are applicable.
\end{abstract}

Keywords: Muscle Dysmorphia, social contagion, males, non-competitive bodybuilders, fore-

${ }^{*}$ Corresponding author. Tel: +34963877032; Fax: +34963877032; e-mail address: elpopla@esp.upv.es 
cast.

\section{Introduction}

The prevalence of physical fitness among men has risen in recent decades in the new generation. Level of exercise increases physical fitness, which leads to health benefits. However if in excess, it can be associated with the development of psycho-medical diseases.

As a result of desiring the perfect body image, a new pathology can emerge in those cases in which self-image becomes an obsession. This is known as bigorexia or muscle dysmorphia (MD) (Blashfield et al., 1990; Pope et al., 1997; Mosley, 2009; Nieuwoudt et al., 2012), a disorder in which a person becomes obsessed with the idea that he or she is not muscular enough. This disorder affects mainly men (Phillips, 2009). The individuals who suffer it think that their body shape and size is scrawny or too small, which can increase obsessive and negative behaviour related to their appearance. It can also be associated with depression, social anxiety, self-esteem issues and social phobia (Pope et al., 1997; Hitzeroth et al., 2001). However, several studies (Greenberg et al. 2010; Phillips et al. 2010) have concluded that it is unclear as to whether MD co-occurs with other forms of body dysmorphic disorder (BDD), such as plastic surgery or anorexia. Other authors have classified MD as an independent disease entirely, a condition derived from the so-called body image disturbance (Murray et al., 2010).

The causes that explain MD development are not completely known, but there are two key ideas: firstly, it is assumed to be a form of obsessive-compulsive behaviour (Leone et al., 2005); secondly, the effect of media and social contagion (Christakis and Fowler, 2009; Raafat et al., 2009) places pressure on men to conform to an ideal body shape, to the extent that they spend

more time in the gym. Some studies have suggested that distortion and dissatisfaction with body image may relate with MD onset (Lantz et al., 2001; Mccabe et al., 2005; Martí-González et al., 
2012), which affects not only adult men, but also young boys (Cohane et al., 2001) and mature men (Mayer, 2011).

Previous research works have shown that individuals with MD develop social problems since they attempt to spend more time in the gym, which leads to avoidance of social events and can cause family conflicts, and even loss of jobs. Thus exercise becomes the most important priority in their life and can lead to social isolation (Phillips et al., 1995; Pope et al., 1997; Olivardia, 2001).

The negative MD-related effects and risk behaviours on health consist in excessive supplemental abuse of anabolic androgenic steroids (AAS), unhealthy diet and drug abuse. Clinical studies have shown psychological problems, such as mood changes, which increase aggressiveness and violence of the individuals who have used AAS to increase their muscularity (Pope et al., 2009; Walker et al., 2009). These behaviours are the result of men's dissatisfaction with their body image (French et al., 1995; Greenberg et al., 2010). In particular, it is estimated that athletes who have used anabolic steroids oscillate between 1 and 3 million in the United States (Silver, 2001; Brown, 2005).

Pope et al., (200b) have also claimed that more than 10\% of bodybuilders suffer MD. However, their results also concluded that men with MD vastly differ from normal weightlifters, most of whom present a minor psychopathology (Choi et al., 2002).

Very few studies on the economic and socio-cultural factors that influence individuals to develop excessive gym practice are available. Research shows a positive relationship between household income and sport participants. This means that an individual's income is an important factor in deciding about practicing sport (Eide and Ronan, 2001; Farrell and Shields, 2002; Humphreys and Ruseski, 2011). One explanation of this effect is that culture in western societies considers that men with an ideal body can achieve a better quality of life (Popkin, 2003). Another cause related to MD development is men's intention to increase their attractiveness to other men or women which, according to previous studies (Brown and Graham, 2008; Chaney, 2008), 
may lead to higher gym practice rates among homosexuals. Furthermore, according to Pompper (2010), men are afraid of being feminine and, consequently, the masculinity concept influences men's body shape.

The socio-cultural factors that may influence MD development can be classified into three environmental sources: messages from the family, friends and media (e.g., fashion models, athletes and entertainment) (Olivardia et al., 2000; Ricciardelli and McCabe, 2003; Keery et al., 2004). Cultural values and preferences may influence and shape BDD symptoms (Phillips, 2005). Peer pressure among teenage boys includes extreme cases of bullying (Wolke and Sapouna, 2008), parental comments, and media and society also influence their behaviour. Thus they feel they have to control their body weight and shape from a very young age (Smolak et al., 1999).

Yet despite MD having been recognised as a subcategory of BDD in the DSM IV-TR, there are no standardised medical procedures developed for its treatment. To date, only the cognitive-behaviour therapy (CBT) exists, which is a clinical treatment to reduce BDD symptoms.

For the particular case of Spain, the Spanish General Council of Pharmacists has estimated that around 700,000 people consumed doping substances in Spain in 2011 in order to increase their muscles mass (Salinas, 2011). Although there are no conclusive results, it is estimated that there were around 20,000 Spanish people with dysmorphic disorder in 2011 (Salinas, 2011).

In line with this framework, our study develops a discrete population mathematical model to forecast the prevalence rate of non-competitive bodybuilders at risk of suffering MD in Spain in the next 5 years. For this purpose, economic, emotional and psychological motivations were taken into account to quantify the dynamic behaviour of Spanish non-competitive bodybuilders. The paper is organised as follows: Section II deals with the modelling construction throughout a discrete system of difference equations that represent the population of interest. This section also presents the dynamic changes between populations, hypotheses, data collection and data matching. Section III offers the computations and simulations carried out after assuming several pos- 
sible economic scenarios for forthcoming years. Section IV includes the conclusions and business possibilities.

\section{Methods}

Spanish adult men attending gyms aged between 18 to 40 years comprised the target study population. Although some authors consider the typical range of onset to start from 15 to 30 years (Facchini, 2006; Pope et al., 2000a), recent studies (Mayer, 2011) have shown that mature men aged up to 40 years are also affected by MD.

In order to analyse the MD pathology of non-competitive bodybuilders, the Test Breve de Vigorexia (TBV questionnaire) (Baile, 2005) was applied. This questionnaire consists in 10 questions that measure several levels of non-competitive bodybuilding activity, as well as individuals' psychological dependence on such practice. All 10 questions provide three possible answers and score one of the following 3 values: $-1,0$, or +1 . The total questionnaire score varies within the $[-10,+10]$ interval.

Individuals were classified into three categories according to their score (obtained from the sum of the participants' answers in the questionnaire) as follows:

- $\quad$ N: defined as incidental non-competitive bodybuilders; those men who obtained a questionnaire score that was equal to or lower than 2 points, and who reported that they did 1 or 2 workout sessions per week.

- S: frequent non-competitive bodybuilders: those men with a questionnaire score of 3 or 4 points, and who reported having bodybuilding sessions at least 3 times per week. 
- A: non-competitive bodybuilders at risk of developing MD obtained a questionnaire score higher than 5 points and also reported practicing non-competitive bodybuilding more than 3 times per week.

\section{Participants}

We passed the questionnaire twice, once in 2011 and again in 2012, in both locations: the public gym of the Polytechnic University of Valencia and a private multi-located gym. Participants were asked to complete the TBV which comprised 10 questions.

The stratified sampling method based on the Spanish population's age was applied. Table 1 shows not only the data collected from the two samples, but also the classification of Spanish non-competitive bodybuilders by subpopulations after adjusting statistically using the data of both the Spanish National Statistical Institute (INE) and Ferrando and Goig (2010).

Table 1 showed that the proportion of frequent non-competitive body builders (S) and non-competitive body builders at risk of suffering MD (A) increased considerably in Spain from 2011 to 2012. Thus the mathematical model was built according to the hypothesis: the increase in this pathology occurs due to economic, emotional and social contagion drivers.

\section{[TABLE 1]}

\section{Mathematical model}

The purpose of this section was to develop a discrete mathematical model to allow us to determine the behaviour of bodybuilders during the 2012-2015 period.

As mentioned in the previous section, the study population was divided into three categories according to the scores participants obtained in the TBV questionnaire (Baile, 2005). Attention 
was paid to forecast the number of incidental non-competitive bodybuilders $(\mathrm{N})$, frequent noncompetitive bodybuilders (S), and those men at risk of developing MD (A).

The non-competitive bodybuilder's behaviour is dynamic, which means that it can vary over time, and embraces interactions and changes of individuals among subpopulations. Accordingly, the mathematical model used to describe this dynamics is a system of difference equations whose unknowns are:

$N_{n}=$ Number of males that are incidental non-competitive bodybuilders aged $[18,40]$ in year $n$.

$\mathrm{S}_{\mathrm{n}}=$ Number of males that are frequent non-competitive bodybuilders aged $[18,40]$ in year $\mathrm{n}$.

$A_{n}=$ Number of males non-competitive bodybuilders at risk of suffering MD aged $[18,40]$ in year $n$.

The total population (P) at time $n$ was given by:

$$
P_{n}=N_{n}+S_{n}+A_{n}
$$

The dynamic behaviour of non-competitive bodybuilders was based on their transit between the subpopulations explained by the coefficients that needed to be modelled according to the economic, emotional and contagion hypotheses.

The study period began in 2011, when the first study sample was obtained, after which time any variation among subpopulations $\mathrm{N}, \mathrm{S}$, and A was estimated for the interval [n, n+1].

\section{Hypotheses of the model}

The following hypotheses of the model are presented: 
1-The individuals are included in the model only as normal-non-competitive bodybuilders $(\mathrm{N})$ according to two hypotheses:

a. Male non-competitive bodybuilders aged from 18 years. It is assumed that the increase in incidental non-competitive bodybuilders $(\mathrm{N})$ and frequent non-competitive bodybuilders $(\mathrm{S})$ in year $\mathrm{n}$ is equal to the Spanish birth rate in that year (n-18), while it is 0 for subpopulation A.

b. As a result of economic improvement, if it occurs, the population invests more money in practicing sports, which increases the $\mathrm{N}$ subpopulation (Eide and Ronan, 2001; Farrell and Shields, 2002; Humphreys and Ruseski, 2011).

2-The non-competitive bodybuilders leave the model in year $\mathrm{n}$ given three possible scenarios:

a. The non-competitive bodybuilders are older than 40 years and their number lowers in year $\mathrm{n}$.

b. As a result of the economic crisis, a proportion of the $\mathrm{N}$ subpopulation emigrates abroad and gives up practicing bodybuilding.

c. Because of economic deterioration, incidental non-competitive bodybuilders practice less bodybuilding since it may be considered a luxury good. However, the level of practice of subpopulations $\mathrm{S}$ and A does not lower.

3-The individuals can only move from one category or subpopulation to another (Christakis and Fowler, 2009; Raafat, et al., 2009). Thus, the $\mathrm{N}$ bodybuilders can be transferred to subpopulation $\mathrm{S}$, and vice versa. A possible recovery transfer from frequent non-competitive bodybuilders (S) to incidental non-competitive bodybuilders is also assumed (N). 
Individuals' transits are due not only to their own characteristics, but also to their environmental conditions (economic and personal drivers) that define their behaviours (Girard, 2008; Christakis and Fowler, 2009; Raafat, et al., 2009).

Hence, transits among subpopulations are due to:

a. Influence of personal experiences in childhood (bullying) (Wolke and Sapouna, 2008; Boyda and Shevlin, 2011), and looking to improve their sex appeal (Brown and Graham, 2008; Chaney, 2008; Pompper, 2010) or to rebuild their personal life after divorce or being deprived of a person (Duato and Jódar, 2011), defined by

b. The combination of opposite drivers, such as, emotional impact and economic recovery, . $\alpha_{r}$

c. Influence of personal relationships, especially with MD non-competitive bodybuilders (A), is a determinant of people's habits and behaviours; e.g., their diet and the special products they consume, $\quad$ (Christakis and Fowler, 2009; Raafat et al., $\gamma_{1}, \gamma_{2}$

2009).

d. Influence of economic improvement, if it happens (improved unemployment rate), combined with rebuilding personal life, can produce a backward move from excessive non-competitive bodybuilders $(\mathrm{S})$ to normal non-competitive bodybuilders $(\mathrm{N})$, (Popkin, 2003). $\alpha_{2}$ 
The model dynamics can be described by the following equations:

$$
\begin{gathered}
N_{n+1}-N_{n}=b_{1} N_{n}-d_{1} N_{n}+\alpha_{2}(n) S_{n}-\alpha_{e} N_{n}-\gamma_{1} N_{n}-\alpha_{f} N_{n}+\alpha_{u}(n) N_{n} \\
S_{n+1}-S_{n}=b_{2} S_{n}=d_{2} S_{n}-\alpha_{2}(n) S_{n}+\alpha_{e} N_{n}+\gamma_{1} N_{n}-\alpha_{t}(n) S_{n}-\gamma_{2} S_{n} \\
A_{n+1}-A_{n}=-d_{3} A_{n}+\alpha_{t}(n) S_{n}+\gamma_{2} S_{n}
\end{gathered}
$$

and also as a more compact form $\mathrm{X}(\mathrm{n}+1)=\mathrm{A}(\mathrm{n}) \mathrm{X}(\mathrm{n})$, where

$\mathrm{X}(\mathrm{n})=(\mathrm{N}(\mathrm{n}), \mathrm{S}(\mathrm{n}), \mathrm{A}(\mathrm{n}))^{\mathrm{T}}$ is the population vector and $\mathrm{A}(\mathrm{n})$ is the matrix of the transit coefficients given by:

$$
A(n)=\left[\begin{array}{ccc}
1+\alpha_{u}(n)+b_{i}-\left(d_{1}+\alpha_{e}+\gamma_{1}+\alpha_{f}\right) & \alpha_{2}(n) & 0 \\
\alpha_{e}+\gamma_{1} & 1+b_{2}-\left(d_{2}+\alpha_{2}(n)+\alpha_{i}(n)+\gamma_{2}\right) & 0 \\
0 & \alpha_{i}(n)+\gamma_{2} & 1-d_{3}
\end{array}\right]
$$

and can also be expressed by the model dynamics (Figure 1).

The values of all the parameters were estimated from the different sources of information and hypotheses, except transit ${ }_{\gamma_{1}}$, which was adjusted by the model.

[FIGURE 1]

The following model parameters were estimated: 
- $b_{i}$, is the birth rate of the Spanish population in 1993 per category $(\mathrm{i}=1,2,3)$ in 2011 (INE, 2009). The birth rate was assumed to be distributed between subpopulations $\mathrm{N}$ and $\mathrm{S} ; 80 \%$ of the incoming non-competitive bodybuilders within the age interval $[18,40]$ belonged to subpopulation $\mathrm{N}$, while the remaining $20 \%$ were included in the model as subpopulation S. Hence the transit coefficients are measured as follows: $b_{1}=0.8 *(10.66 / 1000)=0.008528$; $b_{2}=0.2 *(10.66 / 1000)=0.002132$ and $b_{3}=0$.

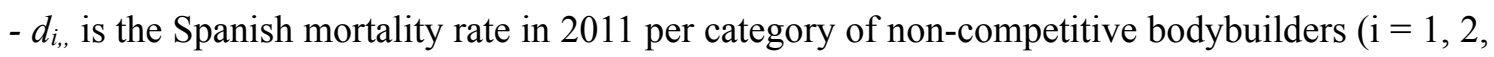
3). This rate was assumed to remain constant for the 2011-2015 period (INE), where $d_{i}=$ $(8.8 / 1000) / 3=0.00293$

- $\quad$ is the Spanish unemployment rate in the year n. For 2011, the unemployment rate was taken $u_{n}$

from the INE data. For the years 2012 and 2013, the economic forecast was taken from the Organisation for Economic Cooperation and Development (OECD) and the Spanish Savings Bank Foundation (FUNCAS). Given the grave economic uncertainty in Europe, the above institutions have not forecasted the unemployment rate in Spain for 2014 and 2015. Thus two possible scenarios were assumed from the OECD and the FUNCAS forecast. Two more scenarios were also considered, an optimistic one (more optimistic than OECD and FUNCAS) and another pessimistic one (more pessimistic than OECD and FUNCAS). Thus, a sufficient spread of economic uncertainty was assumed in the proposed scenarios covering the real unemployment behaviour during the future period of 2013-2015.

- $\quad$ is the emigration rate caused by unemployment in Spain. In 2011, 150,000 people left Spain $\alpha_{f}$

to look for work abroad. Of this number, 5\% were non-competitive bodybuilders (Ferrando and 
Goig, 2010), thus $=(0.05 \times 150,000) / 537,064=0.014$. It can be assumed that the population $\alpha_{f}$

who emigrated was incidental non-competitive bodybuilders $(\mathrm{N})$, and that this rate remained constant for the 2011-2015 period (Arango, 2009).

- $\quad$ is the influence of the economy on non-competitive bodybuilding practice. From the $\alpha_{u}(n):$

data observed in previous years of both the INE and Ferrando and Goig (2010), it is assumed that for each $1 \%$ reduction in the unemployment rate, the $\mathrm{N}$ category increases $0.4 \%$ in year $n$; and that for each $1 \%$ increase in the unemployment rate, the $\mathrm{N}$ category lowers $0.2 \%$ in year $\mathrm{n}$.

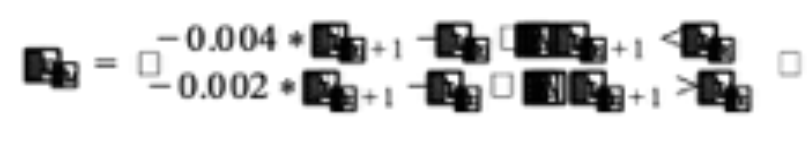

- $\alpha_{2}(n):$ is the rate of possible recovery of subpopulation S estimated as the sum of two non-neg-

ative components: economic ( $\underset{\alpha_{21}}{\text { ) and/or personal life recovery }} \underset{\alpha_{22}}{ }$ ).

- $\alpha_{21}$, if the economy improves, the physical activity practiced by non-competitive bodybuilders

diminishes as they will have less spare time because they work more hours. Thus, $80 \%$ of the 
jobs produced by possible economic recovery (estimated through the INE's annual unemployment rate) is absorbed by the population whose age falls within the interval $[18,40]$, of whom 5\% are non-competitive bodybuilders (Ferrando and Goig, 2010).

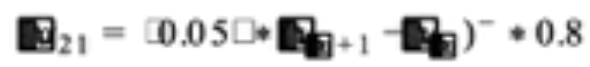

$$
\left(u_{n+1}-u_{n}\right)^{-}=\left\{\begin{array}{ll}
0, & \text { if } \quad u_{n+1} \geq u_{n} \\
u_{n}-u_{n+1}, & u_{n+1}<u_{n} \text { if the economy recovers }
\end{array}\right\} \text { (5) }
$$

-The second component, , determines the transit rate from $\mathrm{S}$ to $\mathrm{N}$ by the improvement in their level of self-esteem through their rebuilt personal life by coupling. ${ }_{\alpha_{22}}$ was estimated as the $5 \%$ proportion of non-competitive bodybuilders of the whole Spanish population whose ages fell within the interval $[18,40]$ (Ferrando and Goig, 2010) and who rebuilt their life, estimated by the marriage rate in Spain in 2008.

Hence, $\alpha_{22}=0.05 * 0.7796=0.03898$. It is assumed that this rate remains constant for the shortterm study. 
- ${ }_{\alpha}$ is the rate of emotional status. Emotions and past experiences may define non-competitive bodybuilders' attitudes motivated mainly by low self-esteem. The emotional rate is estimated as the combination of the weighted average of two addends corresponding to the proportion of non-competitive bodybuilders practices according to two significant age intervals: $[18,25]$ corresponding to those bodybuilders living with their parents; $[26,40]$ defined by the non-competitive bodybuilders assumed to be economically self-sufficient.

- $\quad$ is estimated as the proportion $(9.06 \%$ (INE, 2011)) of Spanish people aged within the in$\alpha_{e 1}$

terval $[18,25], 5 \%$ of whom are non-competitive bodybuilders and have a low level of selfesteem as a result of past experiences, such as a childhood trauma (4\%) (Wolke and Sapouna, 2008), or they hope to improve their physical attractiveness (8\%) (Hönekopp et al., 2007; Brown and Graham, 2008; Pompper, 2010; Varangis, et al., 2012) and others 1\% (emotional drawbacks). In all cases, individuals are pushed to the bodybuilding practice. Then is $\alpha_{e 1}$

weighted as $1 / 3$ of $\quad .(9.06 \% / 25.63 \%=1 / 3)$, where $9.06 \%$ is the rate of Spanish men aged $\alpha_{e}$

$[18,25]$ years in 2011 (INE), and $25.63 \%$ is the rate of Spanish men aged [26, 40] years (INE).

$\left[\mathrm{C}_{1}=0.33 *[0.0906 * 0.05 * 0.13 \square=0.0001943\right.$ 
-Then $\alpha_{e 2}$ is the proportion of Spanish people whose age falls within the interval $[26,40]$ who are non-competitive bodybuilders (5\%) and who experience any of the following statuses: divorce (35\%), childhood trauma (4\%) (Wolke and Sapouna, 2008), or they look to improve their physical attractiveness (8\%) (Hönekopp et al., 2007; Brown and Graham, 2008; Pompper, 2010; Varangis, et al., 2012), and others 1\% (emotional drawbacks).

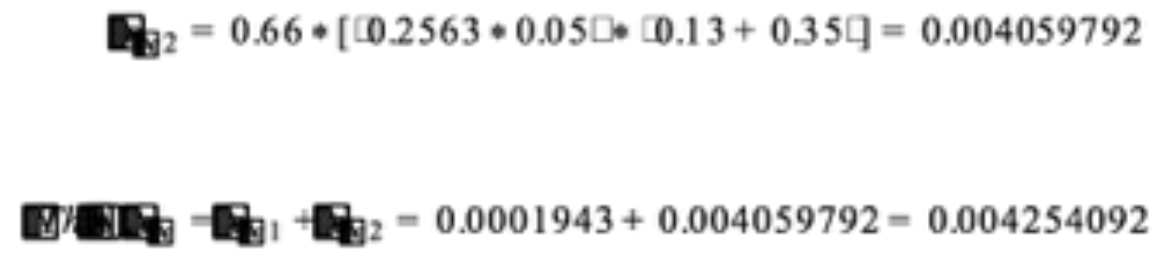

- $\quad$ is the rate of transit from excessive non-competitive bodybuilders (S) to the non-competiti$\alpha$,

ve bodybuilders suffering MD (A) as a result of the combination of two opposite factors, emotional status $\alpha_{\alpha_{e}}$ and economic recovery, which is defined as follows:

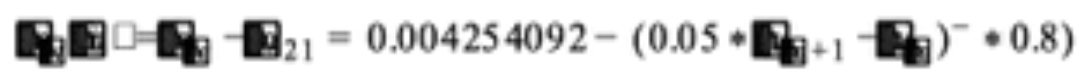

- $\quad$ is the contagion effect from the interaction between non-competitive bodybuilders at risk of $\gamma_{1}$,

developing MD (A) and incidental non-competitive bodybuilders (N), incidental non-competitive bodybuilders' $(\mathrm{N})$ transit to frequent-non-competitive bodybuilders (S). This value was adjusted from the model using the data collected by the two samples cited in the participants section: $\quad=0.08415$ (Christakis and Fowler, 2009; Raafat, et al., 2009). $\gamma_{1}$ 
- $\quad$ is the contagion effect produced by the interaction between subpopulations A and S. Then $\gamma_{2}$,

frequent non-competitive bodybuilders (S) transit to non-competitive bodybuilders at risk of suffering MD (A). is assumed constant for all the study years. It is assumed that this coeffi$\gamma_{2}$,

cient becomes twice the value given the fact that the $\mathrm{S}$ non-competitive bodybuilders are $\gamma_{1}$

more likely to mimic A bodybuilders as a result of the "mirror effect" (Christakis and Fowler, 2009; Raafat, et al., 2009). After matching the data, the value found was $=2^{*}$.

It is important to remark that the robustness of the model versus a change is studied in contagious parameter in the Results section. $\gamma_{2}$

\section{Results of the model}

The mathematical model allows us to forecast subpopulations $N(n), S(n)$ and $A(n)$ in any year $n$ by computing the solution of the difference system (2). As noted while building the model, the economy has a prevalent influence on the subpopulation transits mainly measured by level of unemployment. As the real economic situation of forthcoming years is unknown, several economic scenarios were assumed based on the opinions of prestigious institutions such as FUNCAS and OECD. As the Spanish economy is currently quite volatile, these institutions have provided forecasts only until the end of 2013. As our study period ends in 2015, reasonable economic scenarios were assumed for 2014 and 2015 following the forecasts of FUNCAS and OECD. Furthermore, in order to guarantee that the possible real economic scenario is included 
in the model developed herein, two possible economic scenarios were simulated, Optimistic and Pessimistic, which are respectively more optimistic and more pessimistic than the OECD and the FUNCAS ones (Table 2).

\section{[TABLE 2]}

\section{Simulation of economic scenarios}

Four possible scenarios were simulated according to levels of unemployment. After building the economic scenarios, the following table (Table 3) offers the results simulated by computing the system in the volume of non-competitive bodybuilders classified by subpopulations $\mathrm{N}, \mathrm{S}$ and $\mathrm{A}$.

The prevalence of subpopulations S and A increased over time, irrespectively of the economic scenario, with very few differences found between them. This confirms the robustness of our model versus economic trend.

\section{[TABLE 3]}

Subpopulation S went from 5.97\% in 2011 to the interval [29.11\%, 29.50\%] in 2015 in accordance with the economic scenario. The prevalence rate of non-competitive bodybuilders at risk of suffering MD (A) in Spain increased from 1\% in 2011 to the interval $[11.48 \%, 11.68 \%]$ in 2015 in accordance with the economic scenario.

\section{Sensitivity analysis of the proportionality ratio of social contagion parameter .


In the constructed model, social contagion parameter was assumed to be twice the value of , $\gamma_{2}$

as so: $>$. As knowing how much bigger was than was uncertain, it is advisable to per$\gamma_{2} \quad \gamma_{1}$ $\gamma_{2} \quad \gamma_{1}$

form a sensitivity analysis of this proportionality factor between both parameters. Following the subpopulation A simulation done according to a variation in the proportionality factor and considering the interval $[1,3]$, we obtain: $=$ to $=3 *$.

$$
\begin{array}{llll}
\gamma_{2} & \gamma_{1} & \gamma_{2} & \gamma_{1}
\end{array}
$$

Simulations were performed by assuming that all the parameters remained constant and that the applied unemployment rate was the annual average unemployment rate of all the possible economic scenarios considered (i.e., OECD, FUNCAS, optimistic, pessimistic).

[FIGURE 2]

Figure 2 presents the results. Note that for a fluctuation of social contagion parameter within $\gamma_{2}$

the interval [1,3], the prevalence rate of non-competitive bodybuilders with MD fluctuated within the interval $[6.70 \%, 15.87 \%]$.

The next section summarises the conclusions drawn from the results obtained.

\section{Conclusions}

The present study allows the forecast of the volume of Spanish non-competitive bodybuilders at risk of being affected by MD during the study period [2012-2015]. The development of the mathematical population model considers demographic, economic, emotional and behavioural 
factors and splits the target population into three categories according to the amount of noncompetitive body builder practice they report and their psychological dependence, measured by the TBV questionnaire (Baile, 2005). This population model is founded on the human behaviour of herding and social contagion (Christakis and Fowler, 2009; Rafaat, 2009) and on the study of the dynamic transits among the subpopulations throughout the study period.

As some coefficients, such as the social contagion effect, are difficult to measure accurately, the data from the subpopulation quantities at two different time instants were used, along with the model's response to match uncertain coefficients.

In order to increase the reliability of our results, a sensitivity analysis was performed by studying the change in the results versus the variation in the social contagion parameter. From our results, we can conclude that our model is robust.

One of the main advantages of this model is that it can be applied to any other western country where data are available, and also to another study period in which the hypotheses are applicable.

Unlike previous studies, mainly qualitative and statistical searches for the main drivers and the construction of appropriate questionnaires and their validation (Pope et al., 2000b; Olivardia, 2001; Kanayama et al., 2006; Hildebrandt et al., 2006), this study quantifies the volume of noncompetitive bodybuilders practitioners and bodybuilders at risk of suffering MD in the next few years. For the first time, sociological influences such as human herding and social contagion have been introduced into a study about MD (Christakis and Fowler, 2009; Raafat et al., 2009). Social contagion has also been used to explain the propagation of some socio-epidemics, such as obesity (Christakis and Fowler, 2007) or compulsive shopping (García et al., 2011).

For the sake of honesty, we should acknowledge that one limitation of our study stems from our hypotheses about quantifying the influence of emotional status in non-competitive body builder practice, and the approximate age intervals when men become economically self-sufficient (see 
coefficient ). Finally, as official data on the Spanish coupling rate are lacking, by embracing $a_{e}$

those who are married and non-officially registered couples (or separations), the rate of Spanish coupling (or separations) has been conservatively estimated since we considered only the official Spanish marriage rate (or Spanish divorce rate) data provided.

\section{References}

American Psychiatric Association, Diagnostic and Statistical Manual of Mental Disorders, American Psychiatric Publishing, 2004.

Arango, J. (2009). Después del gran boom: la inmigración en la bisagra del cambio. In E. Aja, J. Arango \& J. O. Alonso (Eds.), La inmigración en tiempos de crisis, Anuario de la Inmigración en España, (In Spanish) (pp.52-73). Barcelona: CIDOB Edicions.

Baile, J. I. (2005). Vigorexia, Cómo Reconocerla y Evitarla. Madrid: Editorial Sintesis.

Blashfield, A. K., Sprock, J., \& Fuller, A. K. (1990). Suggested guidelines for including or excluding categories in the DSM-IV. Comprehensive Psychiatry, 31, 15-19.

Boyda, D., \& Shevlin, M. (2011). Childhood victimisation as a predictor of muscle dysmorphia in adult male bodybuilders. The Irish Journal of Psychology, 32, 105-115.

Brown, J. T. (2005). Anabolic steroids: What should the emergency physician know?. Journal of Emergency Medicine Clinics of North America, 23, 815- 826.

Brown, J., \& Graham, D. (2008). Body satisfaction in Gym-active males: An exploration of sexuality, gender, and narcissism. Journal of Sex Roles, 59, 94-106.

Chaney, M. P. (2008). Muscle dysmorphia, self- esteem, and loneliness among gay and bisexual men. International Journal of Men `s Health, 7, 157-170.

Choi, P. Y. L., Pope, H. G., Jr., \& Olivardia, R. (2002). Muscle dysmorphia: A new syndrome in weightlifters. British Journal of Sports Medicine, 36, 375-376.

Christakis, N. A., \& Fowler, J. H. (2007). The Spread of Obesity in a Large Social Network Over 32 Years, New England Journal of Medicine 357(4): 370-379. 
Christakis, N. A., \& Fowler, J. H. (2009). Connected: The Surprising Power of Our Social Networks and How they Shape Our Lives, Hachette Book Group.

Cohane, G. H., \& Pope, H. G., Jr. (2001). Body image in boys: A review of the literature. International Journal of Eating Disorders, 26, 373-379.

Duato, R., \& Jódar, L. (in press). Mathematical modeling of the spread of divorce in Spain. Mathematical and Computer Modelling, 57(7-8), 1732-1737.

Eide, E. R., \& Ronan, N. (2001). Is participation in high school athletics an investment or a consumption good? Evidence from high school and beyond. Economics of Education Review, $20,431-442$.

Facchini, M. (2006). La imagen corporal en la adolescencia ¿es un tema de varones? Archivo Argentino de Pediatría, 104, 177-184.

Farrell, L., \& Shields, M. A. (2002). Investigating the economic and demographic determinants of sporting participation in England. Journal of Royal Statistical Society, 195, 335-348.

Ferrando, M. G., \& Goig, R. L. (2010). Ideal democrático y bienestar personal. Encuesta sobre los hábitos deportivos en España. Consejo Superior de Deportes. Madrid: Centro de Investigaciones Sociológicas.

French, S. A., Story, M., Downes, B., Resnick, M. D. \& Blum, R. W. (1995). Frequent dieting among adolescents: psychosocial and health behavior correlates. American Journal of Public Health, 85, 695-701.

García, I., Jódar, L., Merello, P., \& Santonja, F. J. (2011). A discrete mathematical model for addictive buying: Predicting the affected population evolution. Mathematical and Computer Modelling, 54(7-8): 1634-1637.

Girard, R. (2008). Mimesis and Theory: Essays on Literature and Criticism, 1953-2005, Stanford University Press.

Greenberg, J. L., Markowitz, S., Petronko, M. R., Taylor, C. E., Wilhelm, S ., \& Wilson, G. T. (2010). Cognitive - behavioral therapy for adolescent body dysmorphic disorder. Journal of Cognitive and Behavioral Practice, 17, 248-258.

Hildebrandt, T., Schlundt, D., Langenbucher, J., \& Chung, T. (2006). Presence of muscle dysmorphia symptomology among male weightlifters. Comprehensive Psychiatry. 47(2): 127-35. 
Hitzeroth, V., Wessels, C., Zungu-Dirwayi, N., Oosthuizen, P., \& Stein, D. J. (2001). Muscle dysmorphia: A South African sample. Journal of psychiatry and Clinical Neurosciences, 55, 521-523.

Hönekopp, J., Rudolph, U., Beier, L., Liebert, A., \& Muller, C. (2007). Physical attractiveness of face and body as indicators of physical fitness in men. Evolution and Human Behavior, 28, $106-111$.

Humphreys, B., \& Ruseski, J. (2011). An economic analysis of participation and time spent in physical activity. The B.E. Journal of Economic Analysis \& Policy, 11(1), 1-36.

Kanayama, G., Barry, S., Hudson, J. I., \& Pope, H. G., Jr. (2006). Body image and attitudes toward male roles in anabolic-androgenic steroid users. The American Journal of Psychiatry, 163, $697-703$.

Keery, H., Van Den Berg, P., \& Thompson, J. K. (2004). An evaluation of the tripartite influence model of body dissatisfaction and eating disturbance with adolescent girls. Journal of Body Image, 1, 237-251.

Lantz, C. D., Rhea, D. J., \& Mayhew, J. L. (2001). The Drive for size: Apsycho - behavioral model of muscle dysmorphia. International Journal of Sports sciences, 5, 71-86.

Leone, J. E., Sedory, E. J., \& Gray, K. A. (2005). Recognition and treatment of muscle dysmorphia and related body image disorders. Journal of Athletic Training, 40, 352-359.

Martí-González, I., Bustos Fernández, J. G., Jordán Contreras, O. R., \& Mayville, S .B. (2012). Validation of a Spanish version of muscle appearance satisfaction scale: Escala de satisfacción muscular. Journal of Body Image, 9, 517-523.

Mayer, C. (2011). The Pleasures and Perils of Living Agelessly.Vermilion, London.

Mccabe, M. P., Ricciardelli, L., Mellor, D., \& Ball, K. (2005). Media influences on body image and disordered eating among indigenous adolescent Australians. Journal of Adolescence, 40, 115-127.

Mosley, P. E. (2009). Bigorexia: Bodybuilding and muscle dysmorphia. European Eating Disorders Review, 17, 191-198.

Murray, S. B., Rieger, E., Touyz, S. W., \& García de la Garza, Y. (2010). Muscle dysmorphia and the DSM - V conundrum: Where does it belong? A review paper. International Journal of Eating Disorders, 43(6), 483-491. 
Nieuwoudt, J. E., Zhou.S., Coutts, R. A, \& Booker, R. (2012). Muscle dysmorphia: Current research and potential classification as a disorder. Psychology of Sports and Exercise, 13 , 569-577.

Olivardia, R, Pope, H. G., Jr., \& Hudson, J. I. (2000). Muscle dysmorphia in male weightlifters: A Case-Control study. The American Journal of Psychiatry, 157, 1291-1296.

Olivardia, R. (2001). Mirror, mirror on the wall, who's the largest of them all? The features and phenomenology of muscle dysmorphia. Harvard Review of Psychiatry, 9 , 254-259.

Phillips, K. A., Mcelroy, S. L., Hudson, J. I., \& Pope, H. G., Jr. (1995). Body dysmorphic disorder: An obsessive compulsive spectrum disorder, a form of affective spectrum disorder, or both. Journal of Clinical Psychiatry, 56,41-51.

Phillips, K. A. (2009). Understanding Body dysmorphic disorder an essential guide (pp. 49). New York, NY: Oxford University press.

Phillips, K. A., Willhelm, S., Koran, L. M., Didie, E. R., Fallon, B. A., Feusner, J., \& Stein, D. J. (2010). Body dysmorphic disorder: Some key issues for DSM-V. Journal of Depression and Anxiety, 27, 573-591.

Phillips, K. A. (2005). The Broken Mirror: Understanding Treating Body Dsymorphic Disorder. (Revised and expanded edition.) New York, NY: Oxford University Press.

Pompper, D. (2010). Masculinities, the metrosexual, and media images: Across dimensions of age and ethnicity. Journal of Sex Roles, 63, 682- 696.

Pope, H. G., Jr., Gruber, A. J., Choi, P., Olivardia, R., \& Phillips, K. A. (1997). Muscle dysmorphia an underrecognized form of body dysmorphic disorder. Psychosomatics, 38, 548-557.

Pope, H. G., Jr., Gruber, A. J., Mangweth, B., Bureau, B., Decol, C., Jouvent, R., \& Hudson, J. I. (2000a). Body image perception among men in three countries. The American Journal of Psychiatry, 157, 1297-1301.

Pope, H. G., Jr., Katz, D. L., \& Hudson, J. I. (1993). Anorexia nervosa and "'reverse anorexia" among 108 male bodybuilders. Comprehensive Psychiatry, 34, 406- 409.

Pope, H. G., Jr, Phillips, K. A., \& Olivardia, R. (2000b). The Adonis Complex: The Secret Crisis of Male Body Obsession. New York, NY: Free Press.

Pope, H. G., Jr., OlivardiaA, R., Gruber, A., \& Borowiechi, J. (1999). Evolving ideals of male body image as seen through action toys. International Journal of Eating Disorders, 26, 65-72. 
Pope, H. G., JR., Hudson, J. I., wood, R. I., Brower, K. J., \& Kanayama, G. (2009). Issues for DSM-V: Clarifying the diagnostic criteria for anabolic-androgenic steroid dependence. The American Journal of Psychiatry, 166, 642- 645.

Popkin, B. M. (2003). The nutrition transition in the developing world. Journal of Development Policy Review, 21, 581- 597.

Raafat, R. M., Chater, N., \& Frith, C. (2009). Herding in humans. Trends in Cognitive Sciences, $13,420-428$.

Ricciardelli, L. A., \& Mccabe, M.P. (2003). Sociocultural and individual influences on muscle gain and weight loss strategies among adolescent boys and girls. Journal of Psychology in the Schools, 40, 209-222.

Rubio Luis, J., \& Baile Ignacio, J. (2006). 'Tendencia vigorexia en un grupo de usuarios de gimnasio". Congreso de la Sociedad Iberoamericana de Psicología del Deporte, México.

Salinas, E. A. (2011). "Síndrome del culturista: "Vigorexia”. Available online http://www.elportaldelasalud.com/sindrome-del-culturista-vigorexia/.

Silver, M. D. (2001). Use of ergogenic aids by athletes. Journal of the American Academy of Orthopaedic Surgeons, 9, 61-70.

Smolak, L., Levine, M. P., \& Schermer, F. (1999). Parental input and weight concerns among elementary school children. International Journal of Eating Disorders, 25, 263- 271.

Varangis, E., Lanzieri, N., Hildebrandt, T., \& Feldman, M. (2012). Gay male attraction toward muscular men: Does mating context matter? Journal of Body Image, 9, 270-278.

Walker, D. C., Anderson, D. A., \& Hildebrandt, T. (2009). Body checking behaviors in men. Journal of Body Image, 6, 164-170.

Woke, D., \& Sapouna, M. (2008). Big men feeling small: Childhood bullying experience, muscle dysmorphia and other mental health problems in bodybuilders. Journal of Psychology of Sport and Exercise, 9, 595- 604. 